\title{
WEAR AND FRICTION BEHAVIOR OF AN SiC PARTICULATE REINFORCED 2124AI COMPOSITE
}

\author{
A.A. Moustafa*, A. Abo El-Nasr* and A. S. Jadi** \\ *Department of Production Engineering and Mechanical Design, \\ Faculty of Engineering, Minoufiya University, Shebin El-Kom, Egypt \\ ** Department of Mechanical Engineering, \\ Higher Institute of Mechanical and Electrical Engineering, Hoon, LIBYA \\ E-mails: albadrawye@yahoo.com
}

\begin{abstract}
The present paper deals with the investigation of wear and friction characteristics of $10 \mathrm{vol} . \% \mathrm{SiC}$ particulate reinforced $2124 \mathrm{Al}$ composite in addition to its unreinforced $2124 \mathrm{Al}$ alloy. A pin-onring apparatus has been employed. The effects of the normal load, sliding speed, and sliding time on mass loss and coefficient of friction were examined. The specific wear energy and the activation energy were also estimated in order to gain more understanding of the mechanisms that control wear in these materials. The present results show, for both materials, that mass loss linearly increases with increasing normal load and sliding time. It is also observed that increasing sliding speed leads to a complicated wear manner. The unreinforced alloy has the greater mass loss when compared with the reinforced composite, but when increasing sliding speed, the unreinforced alloy exhibits minimum values of mass loss. In all cases, the coefficient of friction is greater, for the present composite, than that for the unreinforced alloy. Furthermore, wear mechanisms were investigated and discussed in the light of microscopic observations.

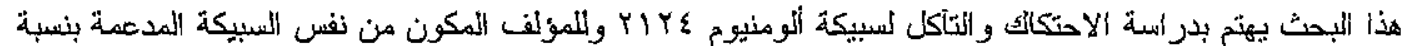

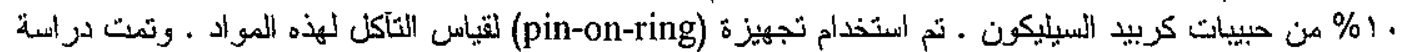

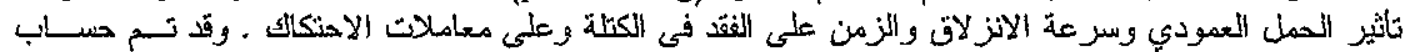

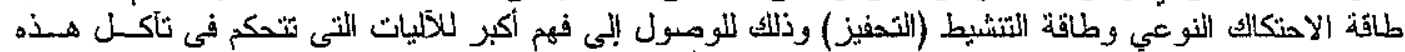

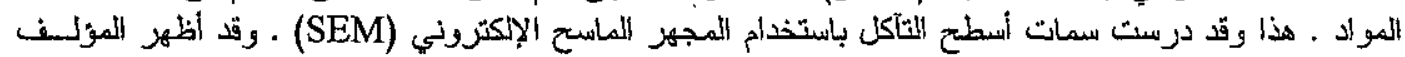

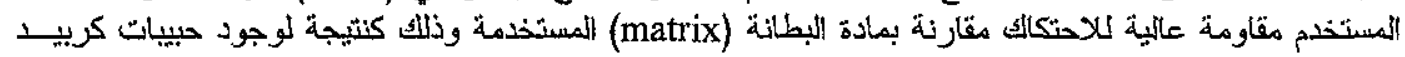

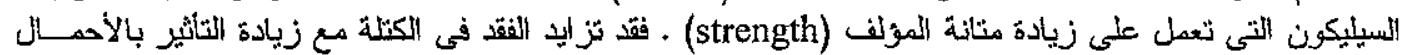

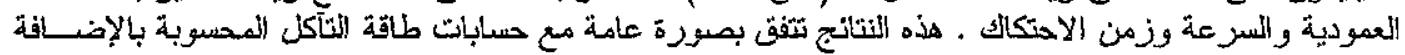

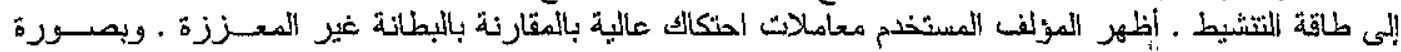

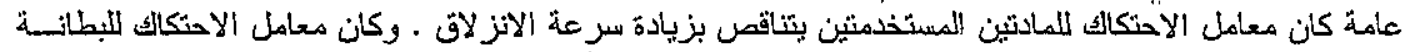

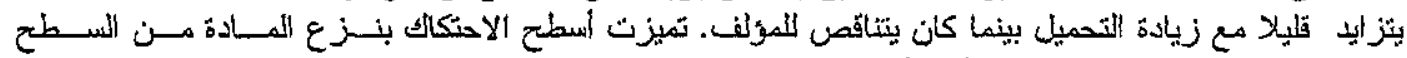

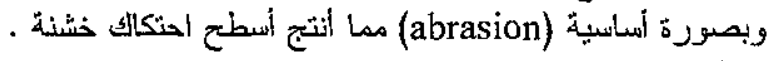

\section{INTRODUCTION}

The past few decades have seen an increase interest in discontinuously reinforced metal matrix composites (MMCs) owing to their promising potential for weight-critical applications [1-3]. Additionally, particulate reinforced MMCs based on Al-SiC systems are gaining increasing importance in miniaturized instrumentation for space, airborne and terrestrial applications, where wear is considered to be an important characteristic in determining the material performance. Particulate reinforced MMCs have a number of interesting mechanical properties, including high stiffness, isotropic, good resistance to wear at high temperatures, and low thermal expansion [4]. Wear behavior of discontinuous SiC$\mathrm{Al}$ alloys (whisker and particulate) has been extensively investigated under different experimental conditions. The mechanics of MMCs have shown many wear mechanisms, mainly delamination and 
plastic deformation and abrasive [5-7]. In these types of materials, the wear rates and mechanisms are mainly controlled by several factors including the applied load, the counter face type of material, the reinforcement particulate size, and the reinforcement volume fraction.

A number of interesting studies [5-16] have tackled the wear behavior including, abrasive, sliding, and erosive wear of different Al base MMCs. Particulate reinforcement of Al-alloys has usually been found to improve the abrasive wear [12], and sliding wear resistance $[12,13]$. It is generally found that the wear behavior of MMCs depends on' the microstructural properties and type of loading contact situation. However, the results found in the literature did show some contradictory. These contradictories may be arise from the differences in testing conditions such as; geometry, load, test duration, material properties, environmental conditions, ...etc. For example, Jiang et al. [9], Martin et al. [10], and Alpas et al. [12] have shown that reinforcements improve resistance to sliding wear and the higher the volume fraction of particles, the better the resistance will be. However, other investigators including Alpas et al., in their other works, [5,13] do not agree. Goldman et al. [14] and Alpas et al. [6] explain their contradictory results by differences in experimental conditions or by the effect of manufacturing process used in producing the composites. The results of Saka and Karalekas [15] and Nath et al. [16] have indicated that the wear rates of particulate composites were lower than those of the matrix alloy, while the coefficient of friction of the composites was higher. It was generally found $[5,6]$ that the sliding wear resistance of the particulate reinforced MMCs and their metallic matrices obey the following relationship where a high load dependence of wear rate is obtained:

$\mathbf{W}^{\prime}=\mathbf{K} \cdot \boldsymbol{F}^{\mathbf{n}}$

where $\mathrm{W}^{\prime}$ is the volumetric wear rate, $\mathrm{K}$ is the wear coefficient, $F$ is the applied load, and $n$ is the wear exponent. Wear behavior of MMCs is found to be a complicated process consisting of different mechanisms [7]. It involves not only mechanical but also thermal and chemical interactions between the surfaces in contact. The contact problem of a dualphase MMCs has been approached in case of abrasive wear [8]. The Hertizian elastic contact was used in estimating the magnitude of tensile stresses that introduced in the surrounding area of contact.

Despite all these contradictory and enormous efforts paid in investigating the wear behavior of particulate reinforced MMCs, they are considered now as a new wear resistant materials and additional efforts should be made in order to gain more understanding of their behavior and to clarify some of the unsolved problems. A series of experiments has been carried out for investigating the wear and friction behavior of unreinforced and reinforced $2124 \mathrm{Al}$ with 10-yol.\% $\mathrm{SiC}$ particulate by using a pin-on-ring apparatus. A considerable attention has been focused on examining and discussing the wear mechanism in the light of the SEM observations.

\section{EXPERIMENTAL PROCEDURES}

\subsection{Material and Specimen}

The materials used in the present investigation were unreinforced $2124 \mathrm{Al}$ alloy and 10-vol.\% silicon carbide particulate (SiCp) reinforced $2124 \mathrm{Al}$ alloy. The 2124 Al alloy has the chemical composition shown in Table 1. The procedure of preparing these materials was powder metallurgy techniques and was received in the as-extruded condition. The specimens were carefully machined from the as received bar parallel to the extrusion direction. All the test specimens were solutionized in argon gas atmosphere at $495^{\circ} \mathrm{C}$ for two hours, water quenched, and then left at room temperature for a minimum of seven days before testing. Such a T4 heat treatment, as has been reported elsewhere [3], will eliminate the residual stress developed during specimen machining and also stabilize the grain size of the composite matrix.

Table 1 Chemical composition of the $2124 \mathrm{Al}$ alloy

\begin{tabular}{|c|c|c|c|c|c|c|c|c|c|}
\hline \hline Elem. & $\mathbf{C u}$ & $\mathbf{M g}$ & $\mathbf{M n}$ & $\mathbf{F e}$ & $\mathrm{Si}$ & $\mathrm{Cr}$ & $\mathrm{Zr}$ & $\mathrm{Ti}$ & $\mathrm{Al}$ \\
\hline $\mathrm{Wt} . \%$ & 4.0 & 1.5 & 0.6 & 0.3 & 0.2 & 0.1 & 0.25 & 0.15 & $\mathrm{Bal}$. \\
\hline \hline
\end{tabular}

\subsection{Wear tests}

Wear tests were carried out using a pin-on-ring apparatus with specimens of the composite and the unreinforced alloy serving as a pin of $5 \mathrm{~mm}$ diameter, mounted in a vertical holder against a rotating hardened steel ring, with $75 \mathrm{~mm}$ diameter, under dry conditions. The apparatus was adjusted to run in a wide range of velocities from 70 to $127 \mathrm{~m} / \mathrm{min}$. For every individual test, the normal contact pressure was kept constant depending on the applied normal load and the nominal projected area of contact. This situation has been achieved by a sufficient running-in period to reach a stable reading of tangential force prior testing. The counterparts in these experiments were fabricated from hardened steel with a bulk hardness of $62 \mathrm{HRC}$. Prior testing, the contact surfaces of the specimens were carefully polished using 600 grit $\mathrm{SiC}$ emery paper in running water, cleaned in ethanol and then dried. To insure that steady state wear was reached, the machined 
specimens were pre-worn until the curvature of the counterpart was copied to the specimen. After running-in, the mass of the specimen was considered as the original mass then formal wear tests were started. The coefficients of friction were obtained periodically by measuring the tangential force on the specimen using a strain gauge force transducer. Mass loss was measured at the end of each test by a high accuracy digital balance, $0.1 \mathrm{mg}$ accuracy. To measure the mean bulk temperature of the sliding surface of the specimen, chromel-alumel thermocouples inserted into three holes locating on the periphery, $\sim 1 \mathrm{~mm}$ from the sliding surface, of the pin was used. Each point on the data curves represents the average of at least three experiments. Finally, the worn surfaces of the specimens were examined using scanning electron microscopy (SEM).

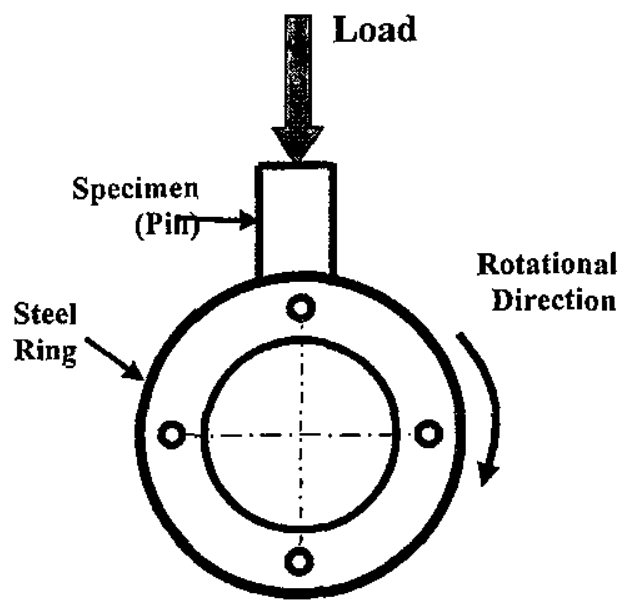

Fig. 1 Schematic draw of a pin-on-ring apparatus used in the present work

\section{RESULTS AND DISCUSSIONS}

\subsection{Microstructure}

A typical SEM micrograph of the cross section of a 10-vol.\% SiCp-2124 Al composite specimen, in the case of as-received condition, is shown in Fig. 2. The average $\mathrm{SiC}$ particulate size was estimated to be $\sim 3$ $\mu \mathrm{m}$. It can be seen from the SEM micrograph that the distribution of the $\mathrm{SiC}$ particulate is nearly uniform along the specimen section and most of the SiC particulates are uniformly laid in the extrusion direction. Some regions with free $\mathrm{SiC}$ particulates are observed in the micrograph. As has been mentioned, these materials were manufactured by powder metallurgy techniques and further extrusion was applied. The extrusion direction is parallel to the vertical edges of the shown micrograph.

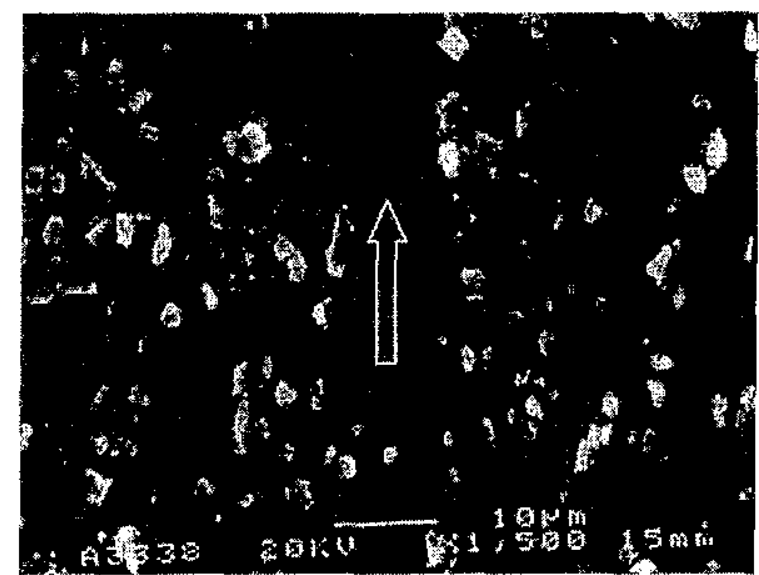

Fig. 2 Typical SEM micrograph of the as-extruded 10 vol.\% SiCp-2124 Al specimen. Arrow points to the extrusion direction.

\subsection{Strengthening Mechanisms in MMCs}

It is now well established that the addition of ceramic particulate results generally in a significant increase in the matrix strength and a considerable decrease in the matrix ductility [2,3]. It is also stated that the properties of the MMCs are very sensitive to the processing technique used in their manufacturing [4]. The existence of broken particulate within the matrix, due to the application of powder metallurgy techniques, decreases the composite strength [17]. Table 2 shows the measured mechanical properties of unreinforced and reinforced $2124 \mathrm{Al}$ with 10-vol.\% $\mathrm{SiC}$ particulate. As shown, the addition of $\mathrm{SiC}$ particulate has resulted in a considerable increase in the ultimate tensile and elastic modulus of the composite.

Table 2 The mechanical properties and primary roughness of the materials used in this work

\begin{tabular}{|c|c|c|c|c|c|c|}
\hline \hline $\begin{array}{c}\text { Test size, } \\
(\mathrm{mm})\end{array}$ & Material & $\begin{array}{c}\sigma_{\mathrm{Y},} \\
\mathrm{MPa}\end{array}$ & $\begin{array}{c}\sigma_{U T S}, \\
\mathrm{MPa}\end{array}$ & $\begin{array}{c}\mathrm{E}, \\
\mathrm{MPa}\end{array}$ & $\begin{array}{c}\text { Hardness, } \\
\mathrm{HV}\end{array}$ & $\begin{array}{c}\text { Roughness, Ra, } \\
\mu \mathrm{m}\end{array}$ \\
\hline \multirow{2}{*}{ Pin, $\phi 5 \times 10$} & $2124 \mathrm{Al}$ & 375 & 456 & 61.5 & 102 & $2.5 \pm 1.5$ \\
\cline { 2 - 6 } & 10 -vol.\% SiCp-2124 Al & 368 & 465 & 72 & 115 & $2.5 \pm 1.5$ \\
\hline
\end{tabular}


A survey of the available scientific literature demonstrates that numerous theoretical models have been developed to correlate the mechanical properties of MMCs with their microstructural characteristics. These models may be loosely grouped into two general groups; load transfer models and matrix strengthening models [17]. The load transfer models were developed on the basis that, the hard and relatively undeformable reinforcements might carry more loads than the relatively soft matrix. Such models have been successfully used to predict the elastic modulus of MMCs.

In the matrix strengthening models, the strengthening effect may be attributed to various microstructural changes experienced by the matrix as a result of the presence of particulates. Based on this, the interactions between particulates and moving dislocations may lead to strengthening in MMCs.

Dislocation strengthening is considered to be an important mechanism in MMCs since a high dislocation density was observed in the vicinity of the particulates [18]. The generation of dislocations in MMCs is generally attributed to the relaxation of the misfit strain between $\mathrm{SiC}$ particulates and the matrix. This misfit strain arises from the difference in the coefficient of thermal expansion $\left(\triangle \mathrm{CT} \mathrm{C}_{\mathrm{i}}\right.$ ) between the matrices and reinforcements $[18,19]$. On the basis of this understanding, the wear behavior of the present composite can be analyzed in terms of the microstructural changes that occurred as a result of the presence of SiC particulate within the matrix grains.

\subsection{Wear Behavior}

Fig. 3 represents the variations in mass loss against normal load, sliding speed, and sliding time, respectively, for both the unreinforced $2124 \mathrm{Al}$ and 10-vol.\% SiCp-2124 Al composite. It can be seen from Figs. 3.a and 3.c, for both materials, that mass loss linearly increases with increasing normal load and sliding time, respectively. It is observed, in Fig. 3.b, that increasing sliding speed leads to a complex wear manner. Minimum mass loss, $0.0021 \mathrm{gm}$, was observed in testing 10 vol.\% SiCp-2124 Al at 70 $\mathrm{m} / \mathrm{min}, 5.53 \mathrm{~N}$ and 15 min-sliding time. The maximum value was about $0.0129 \mathrm{gm}$ when testing unreinforced alloy at $5.53 \mathrm{~N}$-normal load, 92.5 $\mathrm{m} / \mathrm{min}$-sliding speed and 75 min-sliding time. The unreinforced alloy has the greater values of mass loss when compared with the reinforced composite, but when increasing sliding speed the unreinforced alloy exhibits minimum values of mass loss.
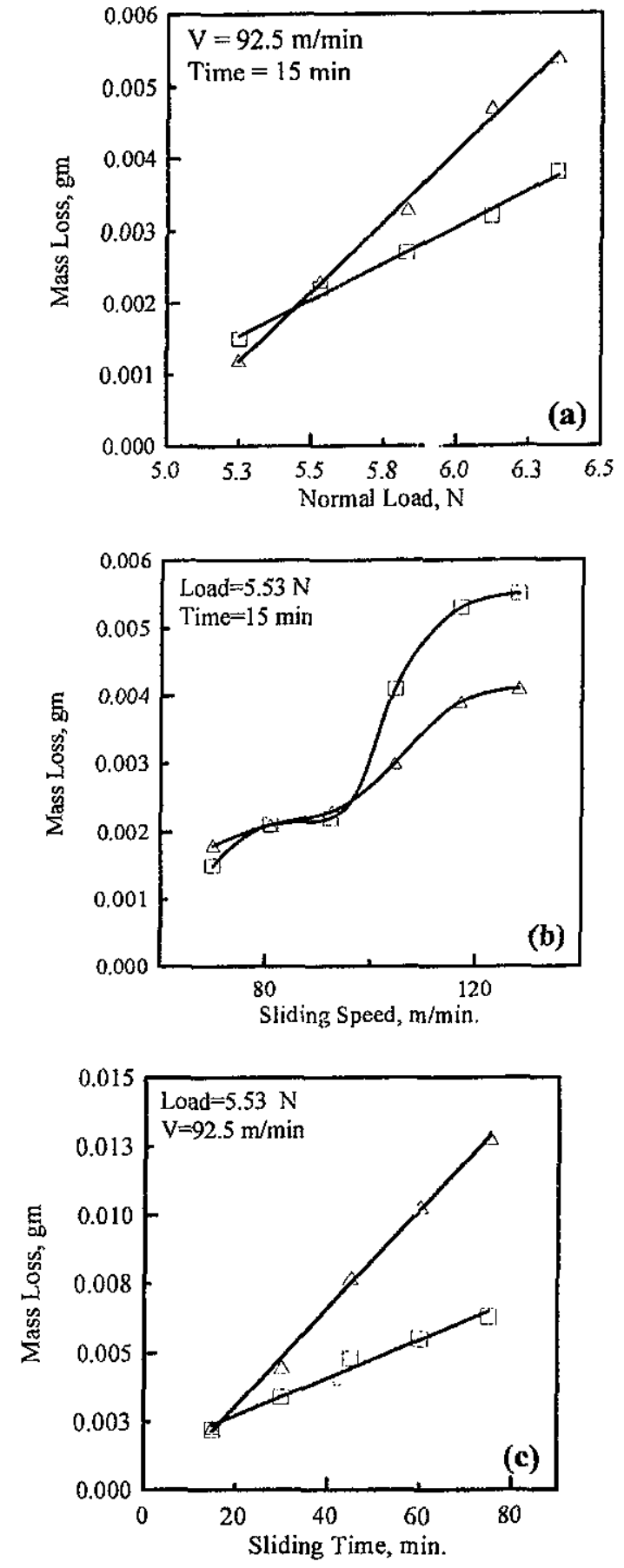

Fig. 3 Mass loss of unreinforced $2124 \mathrm{Al}(\Delta)$ and 10 vol.\% SiCp reinforced $2124 \mathrm{Al}(\mathrm{l})$ against (a) normal load. (b) sliding speed, and (c) sliding time.

It is generally observed that the wear behavior of composite exhibits an increase in the wear resistance with the addition of $10-\mathrm{vol} . \% \mathrm{SiC}$ particulate to 2124 Al matrix over a certain load. As shown in Fig. 3.a, the unreinforced alloy ex'isibits more wear resistance than the composite upto transition load. The value of the transition load is found to be close to $\sim 5.5 \mathrm{~N}$. Based on this result it is expected that different wear mechanisms are existed. It is believed that, when the 
applied load is higher than this transition load, the presence of $\mathrm{SiC}$ particulate decreases the mass loss of the composite not only as a result of the additional strengthening in the matrix microstructure but also the hard particles take a part in resisting penetration, cutting, and grinding by the counterpart. These results can be attributed to the favorable effect of the hard particles in generating a polishing action on the steel counterface and to reducing the tendency of composites to adhesion to steel counterface [20]. Different wear behavior is observed as $\because$ Fig. 3.b when varying sliding speed.

The curves, in the beginning, tends to decrease for Al-SiCp specimens, compared with the unreinforced alloy, as the sliding speed increases, but with further speed increasing, the mass loss of the unreinforced alloy tends to decrease. The following overall inferences may be made, from this graph, within the range of sliding conditions explored. (i) Mass loss increases with increasing the applied sliding speed; however, a nonlinear relationship is observed. (ii) The wear behavior is a complex function of sliding speed since it does not have a monotonic manner when the sliding speed is raised; such a behavior appears to be dependent upon the dominant wear mechanism. (iii) The composites fail under a certain combinations of normal load and sliding speed. Finally, (iv) the load which causes failure during sliding is not fixed at a particular critical value but varies according to the sliding speed and consequently the type of mechanism governing the wear process. It can be concluded that the present MMCs offer a distinctive wear resistance, within the range of the present experimental conditions, compared to its monolithic matrix alloy due to the load carrying capacity of the hard particles. These deductions are in coincidence with those obtained in Ref. [22].

Table 3 shows the measured coefficient of friction as well as the mean bulk temperature raised during running the wear tests. The temperature measured here represents the variation of the mean bulk temperature on the pin surface. It can be noticed from this table that the mean bulk temperature is proportionally increased with increasing the normal load, sliding speed and sliding time. Also, in all cases, the coefficient of friction is greater, for $\mathrm{Al}$ $\mathrm{SiCp}$ composite, than that for the unreinforced alloy. The maximum value was about 0.53 , for Al-SiCp specimen (at load $=5.53 \mathrm{~N}, \mathrm{~V}=81 \mathrm{~m} / \mathrm{min}$. and time $=15 \mathrm{~min}$ ) and the minimum value was about 0.24 for the unreinforced alloy specimen (at load $=5.53 \mathrm{~N}, \mathrm{~V}=128 \mathrm{~m} / \mathrm{min}$. and time $=15 \mathrm{~min}$ ).
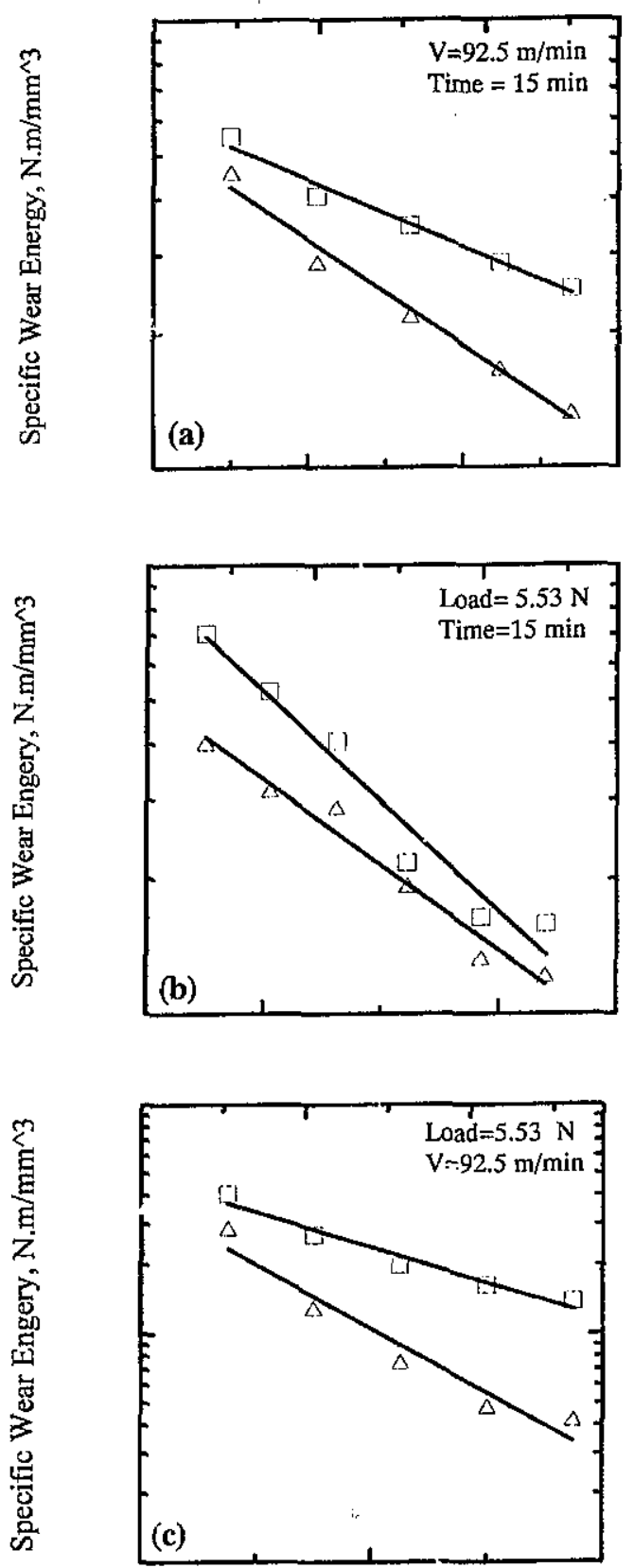

Fig. 4 Specific wear energy of unreinforced $2124 \mathrm{Al}$ (A) and $10 \% \mathrm{SiCp}-2124 \mathrm{Al}$ ( ) against (a) normal load, (b) sliding speed, and (c) sliding time.

The increase in the coefficient of friction for the composite was about one order of magnitude higher than that of the unreinforced alloy. This increase in the coefficient of friction values may be caused by the abrasion action of the reinforcement. It is believed that such a behavior may candidate the $\mathrm{Al}$ SiCp composites to be used in such applications that require minimum mass loss and maximum coefficient of friction. Fig. 4 represents the specific wear energy, on semi logaritbmic scale, in terms of 
the employed experimental variables for the composite and its unreinforced alloy. The specific wear energy here is an indication of the capability of wear resistance of the tested material, i.e. the required energy for ploughing (or pulling) cubic mm from the wear surface.

The specific wear energy $\left(\Delta \mathrm{E}_{\mathrm{fr}}\right)$ can be estimated from the following relation [23]:

$$
\Delta \mathbf{E}_{\mathrm{fr}}=\frac{\mathbf{F}_{\mathrm{f}} \cdot \boldsymbol{v} \cdot \tau \cdot \rho}{\Delta \mathbf{W}}
$$

where $F_{f}$ is the friction force (=friction coefficient $\mathbf{x}$ applied normal force), $\mathbf{v}$ is sliding speed, $\tau$ is sliding time, $\rho$ is the density of pin material, and $\Delta W$ is the weight loss. As seen in the figure, similar trends were observed, the specific wear energy tends generally to decrease as the load, speed and time increase. This behavior is logic as a result of increasing temperature that helps in increasing the material softening. Fig. 5 represents the activation energy (i.e. the energy required for raising the temperature of the pin surface by one degree Celsius) as a function of normal load, sliding speed and sliding time, respectively. The activation energy in these graphs was estimated form the following relation [23]:

$$
\Delta \mathbf{E}_{\text {act }}=\frac{\mathbf{W}_{\mathbf{F}}}{\Delta \mathbf{t} . \mathbf{a}}
$$

where $W_{F}$ is the frictional work, $\Delta t$ is the temperature difference $\left({ }^{\circ} \mathrm{C}\right)$, and $\mathbf{a}$ is pin contact area $\left(\mathrm{cm}^{2}\right)$. The data in Fig. 5.a shows that the variation in the activation energy of both materials is not too large as a result of increasing or decreasing the normal load. Similar trend is observed in Fig. 5.b, where the activation energy of both materials decreases as sliding speeds increase. The activation energy in both Fig. 5.a and 5.b generally exhibits that most of the energy is consumed in changing the surface and sub-surface structure. This part of energy may lead to oxidation of the pin surface ander a certain conditions. In addition, this behavior is logic as a result of increasing the temperature that help in increasing the material sofiening and in turn decreasing the activation energy. Different results are shown in Fig. 5.c, where the activation energy for both materials increases as a result of increasing the sliding time. This trend agree with the physical basis of Eq. 3, where the friction work is a function of sliding distance that increases as the sliding times increase. The results of the Fig. 5 along with those in Fig. 4 indicate that much energy is required for the composite than that for the unreinforced matrix. This gives additional evidence to the thought that the present composite much wear resistant than its unreinforced matrix.

Table 3 The coefficient of friction and the mean bulk temperature difference of the unreinforced and reinforced

\begin{tabular}{|c|c|c|c|c|}
\hline $\operatorname{Load}(\mathrm{N})^{I}$ & $\stackrel{\mu}{\mu}$ & $\stackrel{\mu}{(10 \% \mathrm{SiCp}-2124 \mathrm{~A})}$ & $\begin{array}{c}\Delta \mathrm{T}{ }^{\circ} \mathrm{C} \\
(2124 \mathrm{Al})\end{array}$ & $\begin{array}{c}\Delta \mathrm{T}^{\circ} \mathrm{C} \\
(10 \% \text { SiCp-2124A) }\end{array}$ \\
\hline 5.25 & 0.28 & 0.42 & 32 & 40 \\
\hline 5.53 & 0.32 & 0.46 & 60 & 63 \\
\hline 5.83 & 0.33 & 0.43 & 85 & 105 \\
\hline 6.12 & 0.34 & 0.40 & 106 & $: 36$ \\
\hline 6.35 & 0.30 & 0.38 & 120 & 178 \\
\hline Speed $(\mathrm{m} / \mathrm{min})^{2}$ & & & & $\bar{s}$ \\
\hline 69.6 & 0.35 & 0.51 & 25 & 36 \\
\hline 81.0 & 0.32 & 0.53 & 54 & 51 \\
\hline 92.5 & 0.32 & 0.46 & 60 & 63 \\
\hline 104.4 & 0.28 & 0.43 & 90 & 101 \\
\hline 117.0 & 0.25 & 0.42 & 132 & 142 \\
\hline 127.8 & 0.24 & 0.42 & 169 & 185 \\
\hline \multicolumn{5}{|l|}{ Time (min) ${ }^{3}$} \\
\hline 15 & 0.32 & 0.46 & 60 & 6.3 \\
\hline 30 & 0.28 & 0.44 & 70 & 75 \\
\hline 45 & 0.28 & 0.46 & 110 & 87 \\
\hline 60 & 0.24 & 0.43 & 140 & 120 \\
\hline 75 & 0.26 & 0.40 & 182 & 175 \\
\hline \multicolumn{5}{|c|}{$\begin{array}{l}1-\text { Wear conditions, sliding speed }=92.5 \mathrm{~m} / \mathrm{min} \text { and sliding time }=15 \mathrm{~min} . \\
2-\text { Wear conditions, Normal load }=5.53 \mathrm{~N} \text { and sliding time }=15 \mathrm{~min} . \\
3-\text { Wear conditions, Normal load }=5.53 \mathrm{~N} \text { and sliding speed }=5.53 \mathrm{~m} / \mathrm{min} .\end{array}$} \\
\hline
\end{tabular}
$2124 \mathrm{Al}$ with $10 \% \mathrm{SiCp}$. 

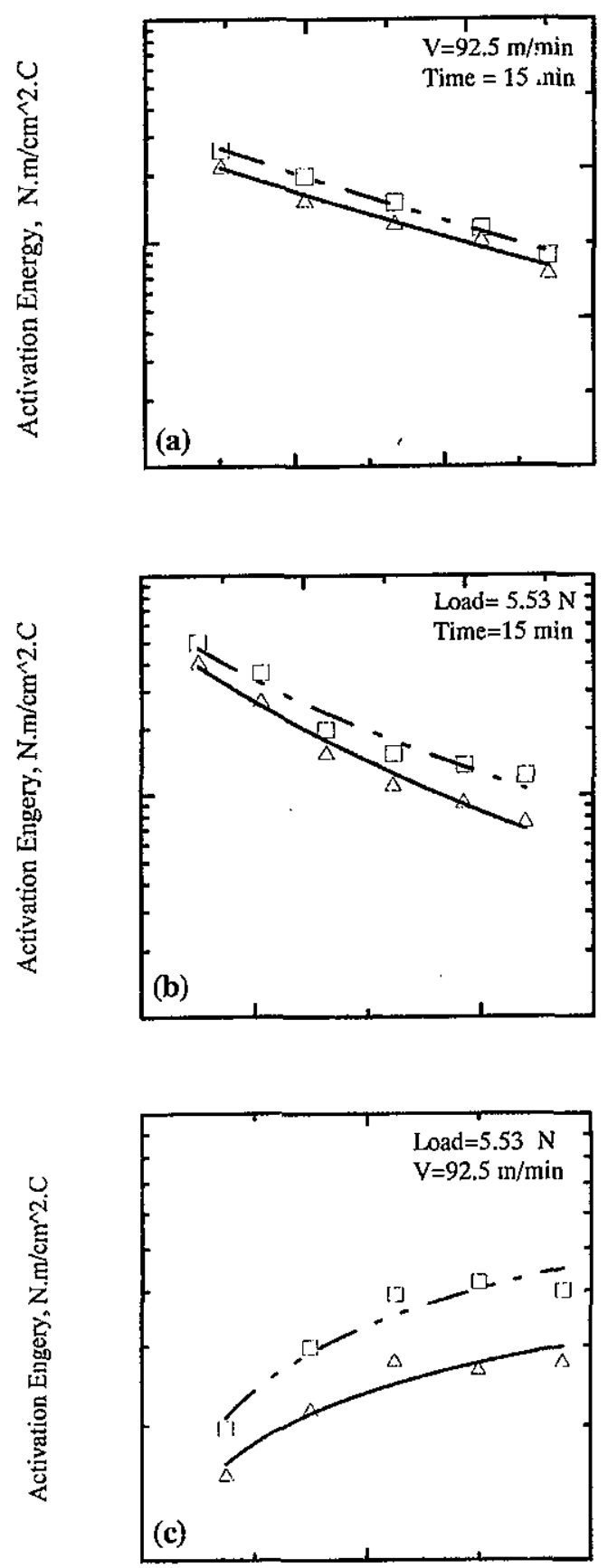

Fig. 5 Activation energy of unreinforced $2124 \mathrm{Al}(\Delta)$ and $10 \% \mathrm{SiCp}-2124 \mathrm{Al}$ ( ) against (a) normal load,

(b) sliding speed, and (c) sliding time.

\subsection{Wear Surface Observations}

The worn surfaces of the present composite were characterized by material removal, mainly abrasion, resulting in a relatively rough surface. Fig. 6 shows an SEM micrograph that several fine deformed wear debris were formed on the worn tracks. The results clearly indicate that the original polished surfaces were rubbed. The $\mathrm{SiC}$ particles indented into the $2124 \mathrm{Al}$ surface were the abrasives that may cause ploughing wear. It is suggested that aluminum transfer is serious under such a load as $6.35 \mathrm{~N}$ and 70 $\mathrm{m} / \mathrm{min}$, abrasion weal is the dominant wear mechanism. Cracks were initiated at the matrixparticulate interface, either at the surface or below the surface. Broken $\mathrm{SiC}$ particulate due to the employing of powder metallurgy and extrusion, as a processing technique, can be confirmed. If the $\mathrm{SiC}$ particulate was not bonded well to the matrix, the wear resistance decreased within the addition of $\mathrm{SiC}$ particulate to the Al alloy and worn surface revealed fracture and extensive debonding at the particulatematrix interface. This led to a greater material removal by particulate fracture and then microcracking. Therefore, the extent of debonding of the reinforcing phase played a critical role in determining the wear behavior of composites. As shown in Fig. 7, the worn surfaces of the pin samples generally had the same features of surface damage in patchy form and longitudinal lines, which were parallel to the sliding direction. However, varying the load had an influence on the distribution of these features. For example, the worn surface at load $6.12 \mathrm{~N}$, and velocity $128 \mathrm{~m} / \mathrm{min}$. Fig. 7, showed a larger area of patchy surface damage than that tested at $5.25 \mathrm{~N}, 70$ $\mathrm{m} / \mathrm{min}$., Fig. 8, but mor ${ }^{\circ}$ parallel longitudinal lines were found at the surfaces tested at the former conditions. The plate-like layers are formed in a ploughing process. These iayers and the edges of ridges separate and wear debris is generated. The longitudinal and transverse cracks often present in the wear scar (Fig. 9). Many of the shear plates, shown in Fig. 9, are formed probably by a severe ploughing process. A plastic flow can also be seen, where distinct sliding tracks are formed and some places are observed where flake-like material is ready to be sheared off. This indicates that the transition from low to mild wear takes place during the experiment, followed by severe as a result of temperature that raised during test. In addition to the presence of silicon carbide particles in the underlying composite, it is suggested that a significant oxidation of the debris had occurred. The adhered debris on the specimen surface displayed a high degree of oxidation. The reinforcement increases the resistance of the alloy to deformation-adhesion, consequently restricting initial transfer of debris to the counterface.

These observations suggest that large wear particles were possibly formed, resulting in wear grooves. Unreinforced alloy showed a worn surface on which there were many small irreg:1lar cracks. These cracks would possibly connect to each other and detach small wear particles. Sliding iracks ate clearly observed, however the existence of surface films can 
be confirmed. Since the surface films prevent metalto-metal contact, mild wear continues in the early stages of the experiment. However, the subsequent wear mode moves to mild wear accompanied by the breakdown of the surface films. At low normal loads, the $\mathrm{SiC}$ particulate served as load-bearing elements, limiting the strains in the Al matrix. In addition, their abrasive action on the steel counter body led to the detachment of iron layers that were oxidized and transferred onto the contact surface. On the contrary, when the normal loads were high enough to fracture the $\mathrm{SiC}$ particulates, large local strain gradients were transmitted to the matrix. Subsurface cracks were then nucleated in the matrix, leading to wear by delamination of sub-surface layers. Under these conditions, the wear rate was mainly controlled by matrix, and it was less sensitive to the presence of SiC particulates.

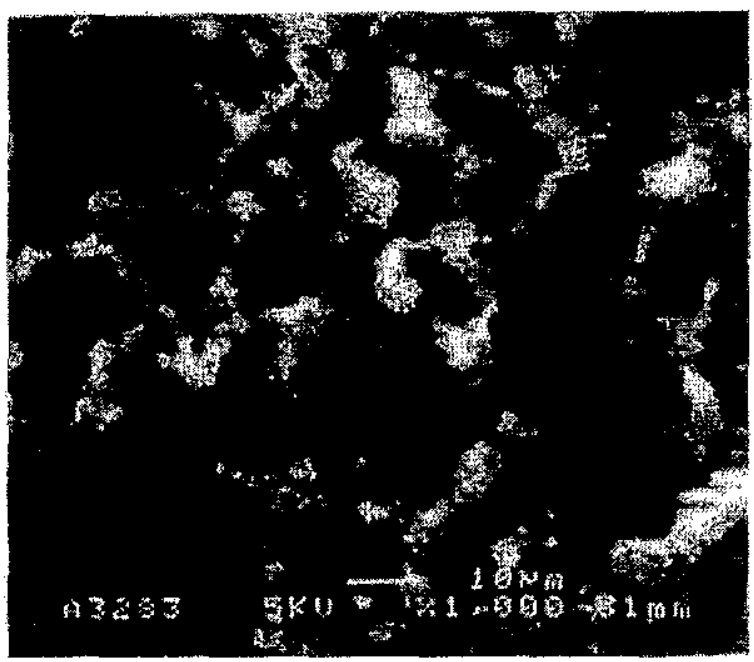

Fig. 6 SEM micrograph of primary wear surface of a composite specimen.

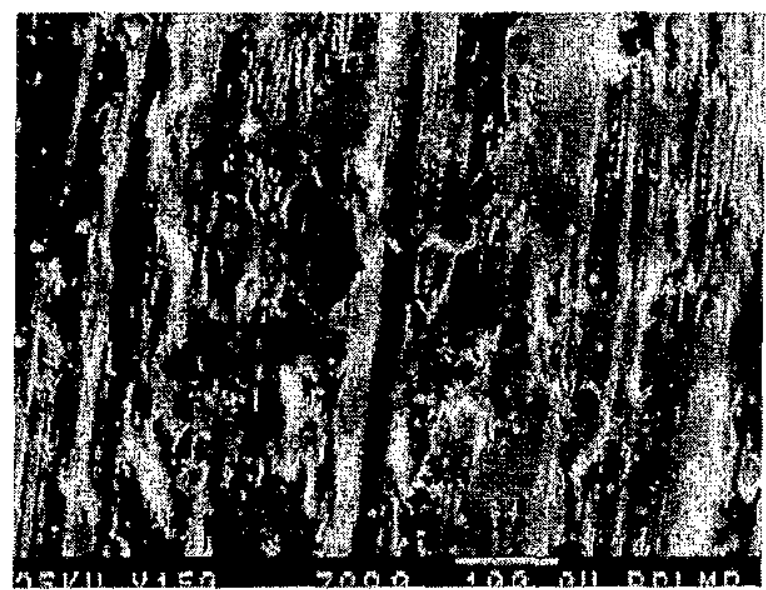

Fig. 7 SEM micrograph of final wear surface of composite specimen.

\section{CONCLUSIONS}

1. The present composite, 10-vol.\% SiCp-2124 Al, offer a distinctive wear resistance compared to its unreinforced matrix due to the load carrying capacity of the hard particles. The mass loss is generally increased with increasing normal load, sliding speed, and sliding time, for both materials. These results agree with the estimated high specific wear energy and high activation energy of the composite.

2. The present composite has exhibited a much better wear resistance and higher coefficient of friction than that of the unreinforced matrix. The coefficient of friction for both materials generally decreased with increasing sliding speed. The coefficient of the unreinforced alloy slightly increased and for the composite, slightly decreased with increasing normal load.

3. Wear surfaces were characterized by material removal, mainly abrasion, resulting in a relatively rough surface. The worn surfaces of the pin samples generally had the same features of surface damage in patchy form and longitudinal lines, which were parallel to the sliding direction. Plastic deformation flow occurred on the wear surface of the composite matrix at an early stage. The formation of fine surface films on the composite pins to reach a steady state much sooner than the alloy and reduced its wear rate. Thickness of the deformed subsurface layer increased with increasing normal load and sliding speed.

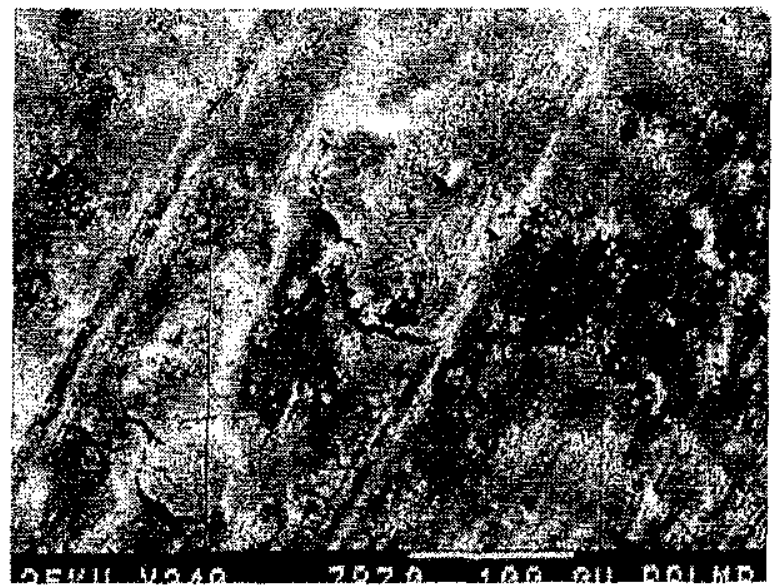

Fig. 8 SEM micrograph of composite specimen tested at $5.25 \mathrm{~N}, 70 \mathrm{~m} / \mathrm{min}$, and $\mathrm{t}=15 \mathrm{~min}$. 


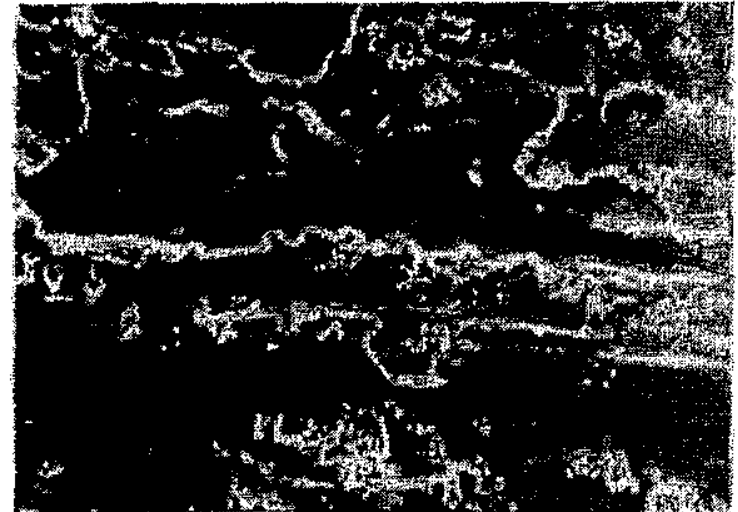

Fig. 9 SEM micrograph of showing surface damage in patchy form with longitudinal lines.

\section{REFERENCES}

[1] Driver, D., "Introduction to Metal Matrix Composites and A review of "Their Potential Uses", (ed. N. Goddard), Test Tech. for MMCs, Technomic, London, (1991), pp: 1-21

[2] Taya, M., Lulay, K.E., Lloyd, D.J., "Strengthening of a Particulate Metal Matrix Composites by Quenching", Acta Metal. mater. 39, no. 1, (1991), pp: $73-87$

[3] Davis, L.C., Andres, C., and Allison, J.E., " Microstructure and Strengthening of Metal Matrix Composites", Mater. Sci. Eng., A249, (1998), pp: 40-45

[4] Xu, Q., Hayes, R.W., Lavernia, E.J., "Mechanical Properties and Fracture Behavior of Layered 6061/SiCp Compo-sites Produced Spray Atomization and Co-Deposition", Acta Mater., v. 47, no. 1, (1999), pp: 43-53

[5] Alpas, A., Zhang, J., Saka, N., and Karalekas, D.P., "Wear of Materials", K.C. Ludema ed., ASME, New York, NY, (1985), pp: 784-794

[6] Alpas, A.T., Zhang, J., "Effect of Microstructure and Counterface Material on the Sliding Wear Resistance of Particulate-Reinforced Aluminum Matrix Composites", Metall. Mater. Trans,, 25A (1994) pp: 969-983

[7] El-Mahallawy, N. and Abdel-Hamid, M., "Effect of Processing Route on the Structure and Wear

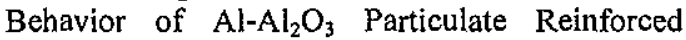
Composites", PEDD-6, Cairo, Feb. 12-14 (2002), pp: 356-397

[8] Simm, W., Freti, S., "Abrasive Wear of Multiphase Materials", Wear129 (1989), pp: 105121.

[9] Jiang, J.K., Tan, R.S., Ma, A.B., "Dry Sliding Wear Behavior of $\mathrm{Al}_{2} \mathrm{O}_{3}$-Al Composites Produced by Centrifugal Force Infiltration", Mat. Sci. and Tech. 12 (1996) pp: 483-488.

[10] Martin, A. Martinez, M.A., Llorca, J., "Wear of SiC-Reinforced Al-Matrix Composites in the Temperature Range 20-200 C", Wear, 193 (1996), pp: 169-179.
[11] Jokinen, A., Anderson, P., "Tribological Properties of PM Aluminum Alloy Matrix Composites", in Adv. in Powder Metall., V. 2, E.R. Andreotti, P.J. McGeehan (Eds.), Metal Powder Industries Federation, Princeton, NJ, (1990), pp. 517-530.

[12] Alpas, A.T., Embury, J.D., "Sliding And Abrasive Wear Resistance of An Aluminum 2014-SiC Particle Reinforced Composite", Metall. Mater., 24 (1990), pp: 931-935.

[13] Alpas, A.T., Zhang, J., "Effect of SiC Particulate Reinforcement on the Dry sliding Wear of Aluminum-Silicon Alloys", Wear, 155 (1992), pp: 83-104.

[14] Goldman, R. W., Segall A. E., Conway, J. C, "The Dry Sliding Behavior of Aluminum Alloys against Steel in Sheave Wheel Applications", Trans. of ASME, vol. 123, October (2001), pp: 676-681

[15] Saka N., Karalekas, D.P., "Friction and Wear of Particle-Reinforced Metal Ceramic Composites", Inter. Conf. on Wear of Materials, Canada, April 1985, pp: 784-793.

[16] Nath, D., Biswas, S.K., Rohatgi, P.K., "Wear Characteristics and Bearing Performance of Aluminum-Mica Particulate Composite Material", Inter. Conf. on Wear of Materials, New York, (1979), pp: 161-167.

[17] Abo El-Nasr, A., "Strengthening Mechanisms in Particulate Reinforced MMCs", PEDAC-7, Alex., Egypt, Feb, 13-15, (2001), pp: 1907-1918.

[18] Arsenault, R.J., "Strengthening and Deformation Mechanisin of Discont-inuous Metal Matrix Composites" Key Engineering Materials, v. 79-80, (1993) pp: 265-278.

[19] Arsenault, R.J., Wang, L., Feng, C.R.," Strengthening of Composites due to Microstructural Changes in the Matrix", Acta Metall. mater., 39 (1991) pp: 47-57

[20] Kwok, J.K.M., Lim, S.C., "High-Speed Tribological Properties of Some Al/SiCp Composites: I. Frictional and wear-rate characteristics", Composites Science and Technology, 59 (1999) pp:55-63

[21] Roy, M., Venkataraman, B., Bhanuprasad, V.V., Mahajan, Y.R., Sundrarajan, G., "The Effect of Particulate Reinforcement on the Sliding Wear Behavior of Aluminum Matrix Composites", Metall. Trans. 23A (1992), pp: 2833-2847.

[22] Ali, S.H.R., Azzam, B.S., Dadoura, H.H., and Bedewy, M.K., "The Influence of Aramid Fibers on The Mechanical Properties and Friction Stability of Advanced Friction Composite Materials", $8^{\text {th }}$ Int. Conf. on Production Engineering Design and Control, PEDAC'2004 Dec. 2004, Alexandria, Egypt

[23] Kostetsky, B.I., "The Structural-Energetic Concept in the Theory of Friction and Wear", Wear, v. 159, (1992), pp: 1-15. 